\title{
ADDED INFECTION IN INDUSTRIAL WOUNDS
}

\author{
BY
}

\author{
BARBARA CLAYTON-COOPER and R. E. O. WILLIAMS
}

\author{
From the Medical Research Council Wound Infection Unit, Birmingham Accident Hospital
}

Sepsis is a complication of industrial wounds that leads to much loss of working time as well as to considerable disability, and the reduction of its incidence is a matter of some importance. In the wider field of general wound infection, it has been found that a proportion of the cases of disabling and fatal sepsis is due to microbes added to the wounds during their treatment. These microbes may be added by the patients themselves or by others, but in both cases the greatest opportunities for their addition occur when the wounds are exposed for treatment and dressing, especially in places where a number of wounds, some of them already infected, are being treated together. Added infection of this kind, traceable to faults in the aseptic routine of dressing, is known to occur in hospital wards and out-patient departments (see 'Medical Research Council War Memoranda' Nos. 6, 1942, and 11, 1944). In the light of the recorded prevalence of sepsis in industrial wounds (e.g. 'Annual Report of Chief Inspector of Factories,' 1942), it is clearly important to know how far factory surgeries resemble hospital departments in this respect.

\section{Methods and Terms Used}

Surveys of wounds presented to hospital outpatient departments have shown that sepsis is associated, in all but 5-10 per cent. of cases, with infection by Staph. aureus, Str. pyogenes, or both (Williams and Miles, 1945). We have accordingly restricted our survey of industrial wounds to these two species, together with any other bacteria, like coliform organisms, which grew easily on the media used to reveal the two pyogenic cocci.

Our bacteriological methods and the definitions of the descriptive terms used are given more fully elsewhere (Williams and Miles, loc. cit.). Briefly, we have sampled both wound and skin with moist swabs. The skin swabs were cultivated aerobically, and the wound swabs both aerobically and anaerobically, on blood agar, though in the preliminary survey recorded below the anaerobic culture was omitted. The wound swabs were also inoculated into cooked meat medium which was subcultured, after two days' incubation, to reveal microbes initially present in small numbers.

We have confined the term Staphylococcus aureus to coagulase-positive staphylococci and have designated as ' micrococci' all other gram-positive cocci that were not streptococci. Streptococcus pyogenes refers to betahaemolytic streptococci belonging to Lancefield's Group $A$, and 'coliform organisms' to gram-negative bacilli, mostly of supposed intestinal origin-e.g. Bact. coli, Bact. aerogenes, Pseudomonas, Proteus, etc.
Organisms isolated within six hours of wounding are described as contaminating, rather than infecting, the wound; infection cannot be presumed to be present within this period since the bacteria have not had time to establish themselves and the tissue response to the invasion has not developed. The presence of Staph. aureus, Str. pyogenes or coliform organisms, in a wound more than six hours old has been regarded as indicative of infection, regardless of the clinical state of the wound. Wounds showing infection without any clinical changes are said to be silently infected; wounds with the signs of inflammation-suppuration, redness and swelling-are described as septic; those with some redness or swelling without frank discharge are described as inflamed. The wounds were regarded as healed when they were closed, dry and free from all except very small areas of scab.

\section{PRELIMINARY SURVEY: GROSS INFECTION RATES}

As a preliminary we surveyed 531 open wounds as they were presented at the surgery in 19 factories of different sizes and with varying first-aid facilities. Most of the wounds sampled were cuts, but some grazes, burns, puncture wounds, boils, septic eyes and septic rashes, were also included. Of the 531 lesions swabbed, 255 (48.0 per cent.) were infected or contaminated with Staph. aureus, Str. pyogenes or both (Table 1). About half the infected wounds were septic; the rest were silently infected. If the freshly inflicted wounds, 19 per cent. of which were contaminated with Staph. aureus, are excluded, the infection rate is $57 \cdot 3$ per cent. These sepsis and infection rates are not reliable as measures of the risk to initially clean wounds treated in the surgery. They are too high because, if a steady rate of wounding is postulated, on any one day the infected patients include a considerable proportion of all the persons wounded during the preceding two weeks whose attendance has been prolonged by sepsis and infection of the wound. Thus in our survey the infection rate increased with the age of the wounds (Table 2): among wounds 1-4 days old it was 48 per cent.; in those 5-14 days old it was 57 per cent.; and it reached 84 per cent. in those more than 14 days old. Str. pyogenes was found more commonly in older wounds than in fresh or recent ones. The uninfected, on the other hand, who tend more rapidly to reach a stage at which attendance at the surgery is unnecessary, will in the main comprise only those injured within the past few days. For these reasons the gross rates probably over-estimate the prevalence of infection in wounds of a given age.

The preliminary survey established the fact that 
TABLE 1

GROSS INFECTION RATES IN FACTORY SURGERIES

\begin{tabular}{|c|c|c|c|c|c|}
\hline \multirow{2}{*}{ Factory } & \multirow{2}{*}{$\begin{array}{l}\text { No. of } \\
\text { wounds } \\
\text { swabbed }\end{array}$} & \multicolumn{3}{|c|}{$\begin{array}{l}\text { Percentage of all wounds infected or } \\
\text { contaminated with- }\end{array}$} & \multirow{2}{*}{$\begin{array}{l}\text { Total percentage } \\
\text { infected or con- } \\
\text { taminated with } \\
\text { Staph. aureus or } \\
\text { Str. pyogenes }\end{array}$} \\
\hline & & $\begin{array}{l}\text { Staph. } \\
\text { aureus } \\
\text { alone }\end{array}$ & $\begin{array}{c}\text { Str. } \\
\text { pyogenes } \\
\text { alone }\end{array}$ & $\begin{array}{l}\text { Staph. aureus and } \\
\text { Str. pyogenes together }\end{array}$ & \\
\hline $\begin{array}{l}\text { All (fresh cuts excluded) } \\
\text { All (fre }\end{array}$ & $\begin{array}{l}531 \\
397\end{array}$ & $\begin{array}{l}38 \cdot 7 \\
45 \cdot 0\end{array}$ & $\begin{array}{l}1 \cdot 6 \\
2 \cdot 3\end{array}$ & $\begin{array}{r}7 \cdot 7 \\
10 \cdot 0\end{array}$ & $\begin{array}{l}48 \cdot 0 \\
57 \cdot 3\end{array}$ \\
\hline $\begin{array}{l}\text { Factories with } 25 \text { or more } \\
\text { wounds sampled: } \\
\qquad \begin{array}{c}1 \\
2 \\
3 \\
4 \\
5 \\
6 \\
7 \\
8 \\
9 \\
10\end{array}\end{array}$ & $\begin{array}{l}47 \\
28 \\
40 \\
27 \\
56 \\
31 \\
25 \\
26 \\
63 \\
26\end{array}$ & $\begin{array}{l}32 \\
39 \\
25 \\
26 \\
48 \\
52 \\
36 \\
54 \\
41 \\
46\end{array}$ & $\begin{array}{l}0 \\
0 \\
8 \\
0 \\
0 \\
0 \\
0 \\
0 \\
8 \\
8\end{array}$ & $\begin{array}{r}4 \\
0 \\
8 \\
22 \\
2 \\
3 \\
24 \\
8 \\
17 \\
15\end{array}$ & $\begin{array}{l}36 \\
39 \\
41 \\
48 \\
50 \\
55 \\
60 \\
62 \\
66 \\
69\end{array}$ \\
\hline
\end{tabular}

TABLE 2

INFECTION RATE AND AGE OF WOUND

\begin{tabular}{|c|c|c|c|c|c|c|c|}
\hline \multirow{2}{*}{\multicolumn{2}{|c|}{ Age of wound }} & & \multirow{2}{*}{$\begin{array}{l}\text { No. of } \\
\text { wounds }\end{array}$} & \multicolumn{3}{|c|}{$\begin{array}{l}\text { Percentage of wounds infected or } \\
\text { contaminated with- }\end{array}$} & \multirow{2}{*}{$\begin{array}{l}\text { Total percentage } \\
\text { infected or con- } \\
\text { taminated with } \\
\text { Staph. aureus or } \\
\text { Str. pyogenes }\end{array}$} \\
\hline & & & & $\begin{array}{c}\text { Staph. } \\
\text { aureus } \\
\text { alone }\end{array}$ & $\begin{array}{l}\text { Str. } \\
\text { pyogenes } \\
\text { alone }\end{array}$ & $\begin{array}{l}\text { Staph. aureus and } \\
\text { Str. pyogenes together }\end{array}$ & \\
\hline $\begin{array}{l}<6 \text { hours } \\
1-4 \text { days } . . \\
5-14 \text { days } . \\
>14 \text { days } . . \\
\text { Not noted... }\end{array}$ & $\begin{array}{l}\cdots \\
\cdots \\
\cdots \\
\cdots\end{array}$ & $\begin{array}{l}\cdots \\
\cdots \\
\cdots \\
\cdots\end{array}$ & $\begin{array}{r}134 \\
167 \\
98 \\
26 \\
34\end{array}$ & $\begin{array}{l}19 \\
41 \\
45 \\
30 \\
50\end{array}$ & $\begin{array}{r}0 \\
3 \\
1 \\
15 \\
0\end{array}$ & $\begin{array}{r}1 \\
4 \\
11 \\
39 \\
3\end{array}$ & $\begin{array}{l}20 \\
48 \\
57 \\
84 \\
53\end{array}$ \\
\hline
\end{tabular}

Note.-Boils, burns and septic rashes are not included in this table.

wounds treated in factory surgeries are infected with the same bacterial species as the larger wounds previously studied in hospital. It gave no information, however, about the influence on infection of the method of wound treatment, the nature of the injury, etc.; the crude rate obtained is certainly affected by the age distribution of the wounds sampled, the readiness with which the workers attend the surgery for the treatment of wounds that have not become septic, and the sort of injuries that predominate in the factory, as well as the form of treatment applied in the surgery.

We have attempted to determine the influence of the dressing technique on the incidence of infection by making a detailed survey in two factories where the type of work done, the size of the factory and of the surgery, and the antiseptic treatments adopted, were very similar, but where there was a notable difference in the aseptic wound dressing technique.

\section{DETAILED COMPARISON IN TWO FACTORIES Surgery Routines}

The two factories (A and B) were both engaged in light engineering. They had well-established medical departments staffed almost entirely by state registered nurses. In both, wounds and 'medical' conditions were treated in the same room; at $\mathrm{A}$ there were separate surgeries for men and women, but at the time of our survey at B all patients there were treated in one room, owing to rebuilding operations. At $A$ there were some 65 first-aid boxes distributed throughout the works, each supervised by a worker with some training in first aid, and 32 per cent. of the patients in our survey had had previous treatment at a box immediately before coming to the surgery. There were no boxes in the shops at B.

The general treatment of the wounds was similar: aqueous acriflavine was used for the majority of clean cuts and for many that showed signs of sepsis. At $\mathrm{A}$, gentian violet was often applied to grazes and obviously soiled wounds. Ichthyol ointment, and at B merthiolate, were used for many septic cuts. Greater use was made at $A$ than at $B$ of adhesive 
plaster ' butterfly' strips to maintain apposition of gaping skin edges, and of immobilization with metal splints and protection with thick linen fingerstalls.

At A, all dressing materials were sterilized; at B they were used as supplied by the manufacturer. A few tests have shown that such dressings are unlikely to contain more than a few aerobic sporebearing bacilli and other non-pathogenic organisms.

Wounds were usually redressed daily, or more often if the dressing became badly soiled or soaked in oil.

The routine for performing the dressings was notably different in the two factories:

For redressings at Factory $A$, the nurse cut through the outer bandage, removed it with her fingers and discarded it into a bin. Forceps, kept in a jar of lysol on the trolley, were used for the remaining manipulations. The nurse removed the inner dressings, dipped a piece of gauze into a bowl of dettol and used it to clean the wound; she then applied another piece of gauze, moistened in antiseptic (usually acriflavine) to the wound as a dressing. The nurse discarded the forceps and applied the bandage by hand. She then recorded the treatment, tidied the top of the trolley, washed her hands and took the forceps to the sterilizer.

With fresh injuries, the skin round the wound and then the wound itself were cleaned, each with a piece of gauze moistened in dettol and held in forceps. If the injured hand was very dirty, the wound was covered with a bandage and the patient instructed to wash the rest of the hand at a basin. The subsequent procedure was as for a redressing.

The routine was followed for the majority of cases. Occasionally forceps were not used and occasionally hand-washing was omitted, but these lapses occurred with any frequency only when the surgery was very busy.

Small pieces of swarf embedded in the tissues were extracted with needles kept in spirit and removed from it with forceps.

At Factory $B$, the nurses were again fairly consistent in their methods but instruments were not used and the nurses' hands were washed only when obviously soiled. For redressings the nurse cut the bandage with scissors kept on the top of the trolley and then removed the dressings with her fingers. Gauze strips, selected by hand from a glass jar and dipped into the antiseptic, were used to clean the wound and were then discarded into an open kidney dish on the top of the trolley. A fresh piece of gauze, also dipped in the antiseptic, was used for the dressing, and the wound was then firmly bandaged. The nurse recorded the treatment and proceeded to the next patient.

With fresh injuries, the wound and the surrounding skin were washed with a piece of cotton-wool moistened in warm but not sterile water, which was kept in an open bowl on the trolley-top and changed three or four times during the morning. Only the skin immediately adjacent to the wound was cleaned, regardless of the state of the rest of the part. The procedure was then as for a redressing.

Embedded swarf was removed with needles kept in a jar of spirit. After use they were usually rinsed in the warm water used for cleaning wounds, dried on a piece of cotton-wool and replaced in the spirit.

\section{Selection of Cases}

The investigation at Factory A lasted, with one month's interval, from August to December, 1943, and that at B from February to March, 1944. The material of the investigation consisted of wounds presented to the surgery within 6 hours of infliction and between the hours of 9.0 a.m. and 12 noon, during which time one of us was present in the surgery. At B we know that no wound was excluded because it was too trivial; the same holds for the great majority at $A$, though a few cases were selected and swabbed by the nursing staff in the afternoons, and here we cannot be sure that the very slight wounds were included. Serious wounds needing hospital treatment were not included. The wounds were swabbed again at each redressing and notes on the clinical state were made by one of us.

The majority of the injuries studied were very small cuts of the hand, but cuts on other parts of the body, as well as a few abrasions, burns and puncture wounds, were included (Tables 3 and 4).

TABLE 3

NATURE OF THE WOUNDS STUDIED

\begin{tabular}{ll|c|c|c}
\hline Nature of wound & $\begin{array}{c}\text { Factory A } \\
\text { 285 cases } \\
\text { per cent. }\end{array}$ & $\begin{array}{c}\text { Factory B } \\
\text { 187 cases } \\
\text { per cent. }\end{array}$ & $\begin{array}{c}\text { Total } \\
\text { 472 cases } \\
\text { per cent. }\end{array}$ \\
\hline Cuts .. &.. & 73.7 & 70.5 & 72.5 \\
Abrasions .. &. & 11.5 & 23.5 & 16.4 \\
Burns .. &. & 0.3 & 0.5 & 0.3 \\
Puncture wounds & 3.0 & 4.5 & 3.6 \\
Not noted &.. & 11.5 & 1.0 & 7.2 \\
\hline
\end{tabular}

TABLE 4

SITE OF WOUNDS

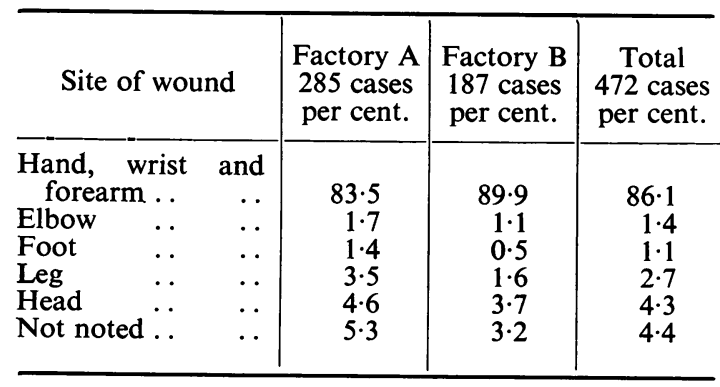

Two hundred and eighty-five cases were studied at $A$ and 187 at $B$ but, owing to the fact that the patients frequently failed to re-attend, by no means all were observed until the wounds were healed (Table 5). We have divided the wounds into four groups according to the completeness of investigation. Group I wounds were followed until they were fully healed; Group II had more than three follow-up swabs taken, but were not followed until healed; Group III had three or fewer follow-up swabs and were not followed until healed; and 
Group IV were not seen after the first attendance. It will be noted that owing to default in attendance of the patients there was, from the point of view of the investigation, a very considerable wastage of the cases admitted.

TABLE 5

\section{NUMBERS OF CASES IN GROUPS I-IV}

\begin{tabular}{|c|c|c|}
\hline Group & Factory A & Factory B \\
\hline $\begin{array}{l}\text { I-Followed until healed } \\
\text { II-4 or more follow-up swabs }\end{array}$ & $\left.\begin{array}{l}88 \\
39\end{array}\right\} 127$ & $\left.\begin{array}{l}48 \\
25\end{array}\right\} 73$ \\
\hline $\begin{array}{l}\text { III-Less than } 4 \text { follow-up } \\
\text { swabs . } \quad . \\
\text { IV-Not seen after first attend- }\end{array}$ & 82 & 51 \\
\hline $\begin{array}{lllll}\text { ance } & \ldots & \ldots & \ldots & \ldots\end{array}$ & 76 &, 63 \\
\hline Total admitted to study & 285 & 187 \\
\hline
\end{tabular}

\section{Results}

Incidence of Infection and Sepsis. Table 6 shows the incidence of infection and sepsis in the two factories. At Factory A, using the more rigorous technique, 44.3 per cent. of the Group I cases became infected before they healed. At Factory B, using the less rigorous routine, 75.0 per cent. of the Group I cases showed infection. This difference is statistically significant $\left(\chi^{2}=10.61, P=0.001\right)$. When Groups I and II are considered together the incidence at A and B was 49.6 and 74.0 per cent. respectively.

The sepsis rates showed a trend in the same direction as the infection rates, but the differences in the incidence were not statistically significant: of Group I cases, 12.5 per cent. at $A$ and 14.6 per cent. at B showed sepsis; the corresponding figures for Group I and II together were $9 \cdot 5$ and $15 \cdot 1$ per cent.

An investigation of wounds in an out-patient department (unpublished) has shown that initial contamination of the wound with Staph. aureus, and the carriage of the same organism on the skin, is associated with the subsequent development of staphylococcal infection. In Groups I and II the initial contamination rate with Staph. aureus was 12.6 per cent. at $A$ and 29.0 per cent. at $B$. The skin carrier rates were $7 \cdot 1$ per cent. and $24 \cdot 7$ per cent. respectively. It is possible, therefore, that the higher infection rate at $\mathbf{B}$ was due to the greater prevalence of staphylococcal contamination and skin carriage, i.e. was determined entirely by factors outside the surgery. This point has been tested by comparing the infection rates at $\mathbf{A}$ and $\mathbf{B}$ in Group I and II patients whose wounds were not initially contaminated and whose skin adjacent to the wound was also free from Staph. aureus (Table 7). Of these cases, $67 \cdot 4$ per cent. became infected at B compared with $36 \cdot 2$ per cent. at $A-$ again a highly significant difference $\left(\chi^{2}=10 \cdot 80, P=0.001\right)$. The difference in infection rates cannot therefore be attributed solely to the difference in contamination or skin carrier rates.

We have already seen that the sepsis rate among a group of wounds presented to the surgery on one day, such as we obtained in our preliminary survey, is an exaggerated index of the sepsis risk to clean wounds treated in the surgery, because of the prolonged attendance of the septic patients as compared with the clean. The sepsis rate for the Group I cases, i.e. patients who were observed for the whole course of healing, provides a more accurate index of this risk, but here again there may be an element of exaggeration. Patients may con-

TABLE 6

INCIDENCE OF SEPSIS AND INFECTION IN THE TWO FACTORIES

\begin{tabular}{|c|c|c|c|c|c|c|c|c|}
\hline \multirow{3}{*}{ State of wound } & \multicolumn{4}{|c|}{ Factory A } & \multicolumn{4}{|c|}{ Factory B } \\
\hline & \multicolumn{4}{|c|}{ Percentage in Groups- } & \multicolumn{4}{|c|}{ Percentage in Groups- } \\
\hline & $\mathbf{I}$ & $\underset{\text { II }}{\text { I+ }}$ & $\underset{\text { III }}{\text { I+ }}$ & $\underset{\text { IV }}{\text { II+ }}+$ & I & II & $\underset{\text { III }}{\text { I+ }}+$ & $\begin{array}{l}\text { II+ } \\
\text { III+ } \\
\text { IV }\end{array}$ \\
\hline Clean, clinically and bacteriologically & $48 \cdot 8$ & $41 \cdot 7$ & $53 \cdot 2$ & $65 \cdot 6$ & $20 \cdot 8$ & $20 \cdot 6$ & $25 \cdot 8$ & $50 \cdot 8$ \\
\hline $\begin{array}{l}\text { Infected with Staph. aureus and/or Str. } \\
\text { pyogenes } \ldots \text {. } . . \\
\text { Infected with pyogenic cocci and/or } \\
\text { coliform organisms } \ldots \\
.\end{array}$ & $\begin{array}{l}38 \cdot 7 \\
44 \cdot 3\end{array}$ & $\begin{array}{l}39 \cdot 4 \\
49 \cdot 6\end{array}$ & $\begin{array}{l}31 \cdot 6 \\
41 \cdot 1\end{array}$ & $\begin{array}{l}23 \cdot 2 \\
30 \cdot 2\end{array}$ & $\begin{array}{l}70 \cdot 9 \\
75 \cdot 0\end{array}$ & $\begin{array}{l}71 \cdot 2 \\
74 \cdot 0\end{array}$ & $\begin{array}{l}66 \cdot 9 \\
69 \cdot 3\end{array}$ & $\begin{array}{l}44 \cdot 4 \\
46 \cdot 0\end{array}$ \\
\hline $\begin{array}{llll}\text { Inflamed }^{*} & \ldots & \ldots & \ldots \\
\text { Septic }^{*} \ldots & \ldots & \ldots & \ldots\end{array}$ & $\begin{array}{l}11 \cdot 4 \\
12 \cdot 5\end{array}$ & $\begin{array}{r}17 \cdot 3 \\
9 \cdot 5\end{array}$ & $\begin{array}{r}11 \cdot 5 \\
5 \cdot 7\end{array}$ & $\begin{array}{l}8 \cdot 4 \\
4 \cdot 2\end{array}$ & $\begin{array}{l}14 \cdot 6 \\
14 \cdot 6\end{array}$ & $\begin{array}{l}19 \cdot 2 \\
15 \cdot 1\end{array}$ & $\begin{array}{l}16 \cdot 9 \\
10 \cdot 5\end{array}$ & $\begin{array}{r}11 \cdot 2 \\
6 \cdot 9\end{array}$ \\
\hline $\begin{array}{llll}\text { No of wounds } & \ldots & \ldots & \ldots\end{array}$ & 88 & 127 & 209 & 285 & 48 & 73 & 124 & 187 \\
\hline
\end{tabular}

Note.-It has been assumed that none of the patients in Groups II-IV became septic, inflamed or infected after default.

${ }^{*}$ i.e. clinical change with or without infection, see p. 146. 
tinue to attend the surgery, and so be included in Group I, for various reasons: (1) The wound is septic and obviously needs treatment. (2) The wound is severe and obviously needs treatment; in these cases there is probably an increased risk of sepsis. (3) The patient may continue to attend for reasons other than those connected with the wound, e.g. hypochondria, attractive surgery conditions, etc. On the assumption that infection may be added during treatment, these wounds are exposed to a prolonged risk of infection. Thus Group I may include an undue proportion of septic wounds, leading to an overestimation of the risk of sepsis, for two reasons: patients may continue to attend because they are septic or markedly liable to sepsis, or they may become septic because they continue to attend the surgery.

TABLE 7

INCIDENCE OF INFECTION IN WOUNDS NOT INITIALLY CONTAMINATED WITH STAPH. AUREUS, WHERE THE PATIENT'S SKIN WAS ALSO FREE FROM THE ORGANISM

\begin{tabular}{|c|c|c|c|c|}
\hline & \multicolumn{2}{|c|}{ No. of cases showing } & \multirow[b]{2}{*}{ Total } & \multirow[b]{2}{*}{$\begin{array}{c}\text { Per- } \\
\text { centage } \\
\text { infected } \\
\end{array}$} \\
\hline & $\begin{array}{c}\text { infection } \\
\text { with } \\
\text { Staph. } \\
\text { aureus }\end{array}$ & $\begin{array}{l}\text { no infec- } \\
\text { tion with } \\
\text { Staph. } \\
\text { aureus }\end{array}$ & & \\
\hline $\begin{array}{l}\text { Factory A.. } \\
\text { Factory B.. }\end{array}$ & $\begin{array}{l}38 \\
29\end{array}$ & $\begin{array}{l}67 \\
14\end{array}$ & $\begin{array}{r}105 \\
43\end{array}$ & $\begin{array}{l}36 \cdot 2 \\
67 \cdot 4\end{array}$ \\
\hline Total .. & 67 & 81 & 148 & $45 \cdot 2$ \\
\hline
\end{tabular}

$\chi^{2}=10 \cdot 80 ; P=0.001$.

On the other hand, if the sepsis rate is calculated from all the patients coming to the surgery, and therefore admitted to the series (Groups I, II, III and IV), irrespective of whether they were followed or not, the value will be too low since some patients may have developed sepsis after defaulting. It is probable, however, that this error is smaller than the error of overestimation because we may reasonably expect that a number of the patients who develop sepsis after default will return to the surgery. In Table 6 we have, therefore, calculated the sepsis and infection rates for Group I, Groups I+II, Groups I+II + III and Groups I+II + III + IV. The true sepsis rate, expressing the average risk of sepsis to a fresh wound attending the surgery, must lie somewhere between the limits of 12.5 and 4.2 per cent. at A, and between 14.6 and 6.9 per cent. at B. Similarly the true infection rate lay somewhere between $44 \cdot 3$ and $30 \cdot 2$ per cent. at $A$ and between 75.0 and 46.0 per cent. at $B$.

Nature of the Infection. In the two factories, considering only the Group I cases, there were 18 wounds that showed sepsis. Ten were infected with Staph. aureus alone, two with Staph. aureus and Str. pyogenes together, and one with Staph. aureus and coliform organisms. From the remaining 5 cases none of these three organisms was isolated, most of them yielding micrococci only. We do not know whether the micrococci were acting as pathogens for these wounds; whether we failed to culture pyogenic cocci that were in fact present, because of inadequate swabbing; or whether, perhaps, the pathogens that would have been accessible to the swab had been killed by the tissue defences. (See Williams and Miles for further discussion of this point.)

The bacteriological findings in the 17 inflamed wounds were similar: Staph. aureus was isolated alone from 7; Str. pyogenes alone from one; coliform organisms alone from 2; and Staph. aureus and coliform organisms together from 4. Three wounds yielded non-pathogens only.

From 34 of the 101 clinically healthy wounds we isolated Staph. aureus alone; Staph. aureus and Str. pyogenes were isolated together from 2; Staph. aureus and coliform organisms from 7; and coliform organisms alone from 5 . The remaining 53 wounds yielded none of these pathogens.

It is clear that Staph. aureus was the predominant pathogen for these wounds; it was isolated from 13 of the 18 septic wounds, from 11 of the 17 inflamed wounds, and from 43 of the 48 silently infected wounds. On the other hand, Str. pyogenes was isolated from only 2 septic, 1 inflamed, and 2 silently infected wounds. It was rare too as an initial contaminant, being present in only 7 of the 472 wounds swabbed, and was observed to persist in only one of these.

Coliform organisms were isolated from only one of the septic wounds, from 6 of the inflamed and from 12 of the silently infected wounds. In a number of cases a moist and sodden appearance of the wound was associated with infection by coliform organisms. We do not know if soddenness in a wound predisposes to infection by these organisms, or whether the sodden appearance is due to the infection; the same appearance was occasionally noticed in wounds infected with Staph. aureus. The wounds in this survey were too small and healed too quickly to allow us to determine whether coliform organisms delayed healing. Nevertheless delayed healing was observed in one wound at A persistently infected with an Achromobacter type of bacillus and in another persistently infected with unidentified coliform organisms.

Conditions predisposing to Infection. In addition to swabbing the skin and wound at the time of first attendance we elicited a history of the accident, including the type of metal when the wound was inflicted by metal, and also noted the cleanliness of the patients' skin and clothing. We have been unable to demonstrate any association between the onset of infection and any of these factors; the number of wounds studied, however, was insufficient to allow us to exclude their influence.

Duration of Treatment. The healing time of the wounds in Group I, classified according to the clinical and bacteriological findings, are given in Table 8. There was a significant difference between the healing times of the clean and septic wounds at both factories; taking the results from both factories together, the clean wounds averaged 5.9 days to healing, the septic 18.2 days (diff. $=12 \cdot 3$ days, $\quad$ S.E. $d= \pm 2 \cdot 1$ days; $\quad$ diff. $/ S . E . d=6 \cdot 0 ; \quad P$ $=<0.001$ ).

The mean healing time for the silently infected wounds was only slightly greater than that for the clean cases. Thus, taking the results from $\mathrm{A}$ and B together, 53 clean wounds took on an average 5.9 days to heal, compared with 6.3 days for the 48 silently infected wounds. At $A$ there was a slight but not significant difference, the silently infected wounds taking 1.3 days longer to heal than the clean; at $\mathbf{B}$ there was no difference. 
TABLE 8

HEALING TIMES OF THE WOUNDS (GROUP I)

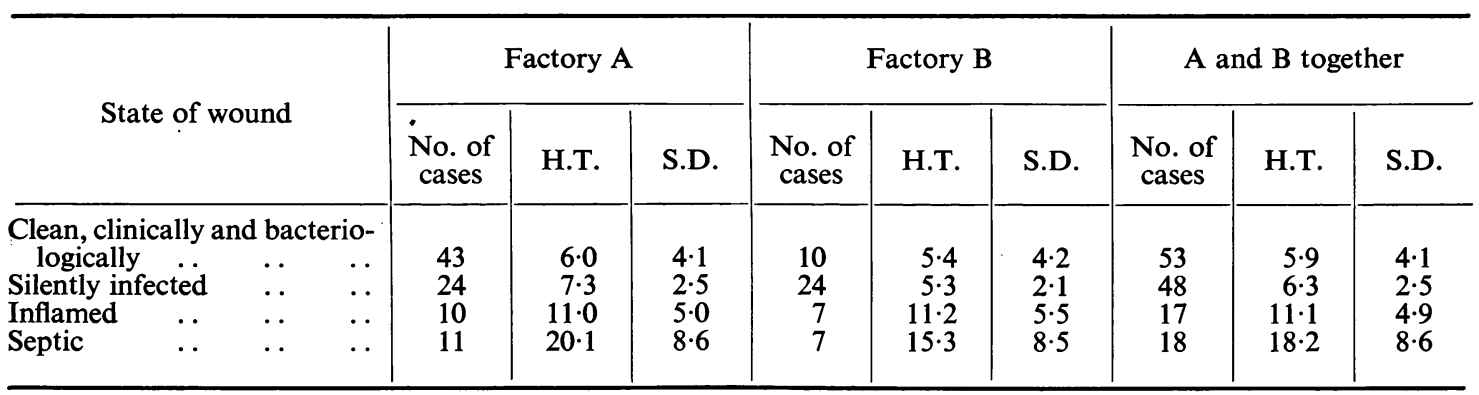

H.T. = healing time, days.

S.D. = standard deviation, days.

Taking the two factories together, the difference is not more than a pointer (diff. $=0.4$ days, $S . E . d$ $= \pm 0.7$ days; diff. $/ S . E_{. d}=0.6$ ) but it bears out our findings in a series of somewhat larger wounds treated at hospital, where 80 bacteriologically and clinically clean wounds took 15.6 days to heal, compared with $18 \cdot 2$ days for 58 silently infected wounds-a significant difference (diff. $/ S . E . d=3 \cdot 5$, $P=<0.001)$.

\section{DISCUSSION}

Sepsis is generally admitted to be a numerically important complication of industrial wounds and is reported to be one of the chief causes of lost working time following accidents (Mock, 1915); to the patient it may mean prolonged and perhaps permanent disability. The wounds that we have surveyed were all small, none requiring hospital treatment; among them the incidence of sepsis was at least 5 per cent. This is not a very high proportion, but it has to be considered in relation to the very great number of minor wounds that occur in the industrial population. There are no accurate figures for the actual number of cuts that do occur, but in Factory A, employing some 6000 workers, there were 3470 attendances at the surgery with fresh cuts etc. in the six-month period JulyDecember, 1943. It is probable that as many more were treated at the first-aid boxes in the factory, i.e. in a year each worker suffered between one and two cuts that needed some sort of treatment. Moreover the sepsis rate that we have recorded is for small wounds and we may expect a higher sepsis rate in larger wounds. For example, unpublished studies at Factory A in the latter half of 1943 showed that of 41 open wounds which at infliction were serious enough to incapacitate the patient for more than 3 days, 13 (32 per cent.) became septic before they healed.

Infection by the two pyogenic cocci is demonstrably responsible for the majority of cases of sepsis (Williams and Miles, 1945). Of the wounds sampled in our preliminary survey 48 per cent. were infected with pyogenic organisms, though only about 25 per cent. were clinically septic. The infection rate increased with the age of the wound and, furthermore, streptococcal infection, which was rare in fresh and recent wounds, was present in 54 per cent. of those more than 14 days old. Similar observations have been made on small wounds studied in hospital: the initial infection is usually staphylococcal; streptococci, on the other hand, commonly flourish only in wounds in which there is established staphylococcal infection (see also Williams and Miles). Our preliminary survey, therefore, suggested that infection was being introduced into the wounds during their healing. In hospital wards, opportunities for cross-infection occur with the greatest frequency during the dressing of the wounds (Miles et al., 1940; Spooner, 1941; Williams et al., 1945). During our preliminary survey in factory surgeries it was clear that numerous opportunities occurred during dressing for a similar transfer of organisms from one wound to another. Obvious instances were the use of fingers for performing wound dressings and the infrequency or total absence of hand-washing between cases, with accompanying contamination of wounds, dressing material, bowls, instruments, etc. Sterilizers, though usually available, were seldom used; bowls and instruments were often inadequately sterilized in spirit or some other disinfectant.

The association between the methods of wound dressing and the incidence of cross-infection, which has been demonstrated in hospital, appears to hold in the factory surgeries, for the infection rate among wounds treated with the more aseptic technique was significantly lower than that where the less rigorous technique was employed. There was, however, one external factor that might have accounted for the difference, namely, the greater number of wounds initially contaminated with Staph. aureus at the factory with the higher infection rate. But the infection rates in patients who had neither contaminated wounds nor Staph. aureus on the skin showed the same significant difference in the two factories. Thus elimination of the bias directly attributable to self-infection still leaves a difference between the infection rates at $\mathbf{A}$ and $\mathbf{B}$. But the initial contamination of the wounds may also have had an indirect effect on the total infection rates in the two surgeries since wounds infected as a result of this contamination are reservoirs for cross-infection. It is arguable that the pre- 
cautionary measures adopted at $\mathrm{A}$ and $\mathrm{B}$ were equally, though not completely, effective and the difference in total infection rates merely reflected the bigger risk of infection (concentration of reservoirs) at $B$. The data, however, give an indication that the risk from the reservoirs that arise as a result of cross-infection is greater than that from self-inflicted wounds. At A 11 of the 22 wounds either initially contaminated or on skin carriers, and 38 of the 105 uncontaminated wounds, became infected; at $B$, the corresponding figures were 23 of 30 and 29 of 43 . If we assume that all the contaminated wounds that became infected did so as a result of self-infection, the cross-infected are $3 \cdot 5$ (38/11) times as numerous as the self-infected at $\mathbf{A}$ and $1 \cdot 3(29 / 23)$ times as numerous at B. But contaminated wounds are exposed to a risk of crossinfection and a number of them may in fact have been cross-infected. Combining the figures for both factories we see (Table 7) that the average infection rate for uncontaminated wounds is $67 / 148$ (45 per cent.). Applying this rate to the 22 contaminated wounds at $A$ and to the 30 at $B$, we should expect that 10 of them at $A$ and 14 of them at $B$ were cross-infected. This would leave one wound at $A$ and 9 at $B$ whose infection was attributable to the initial contamination. On this basis there were 48 times as many cross-infected as self-infected wounds at $A$ and $6 \cdot 2$ times as many at $B$. The true ratio probably lies somewhere between these figures and the smaller ratios quoted above, but they are in any case sufficiently high to suggest that established self-infections constitute a numerically smaller risk than established cross-infections.

None of the other factors that we have studiednature of the accident, nature of the material causing the wound, or cleanliness of the patient's skin or clothing - could be shown to be associated with an increased infection rate, nor were the proportions of the patients in these various classes notably different in the two factories. The wounds, too, were similar in size and site. It is possible that there were other differences in the methods of treating the wounds, apart from the aseptic technique, though none was conspicuous. More wounds were immobilized at $\mathbf{A}$ than at $\mathbf{B}$, but at neither factory did such wounds form more than a small proportion of the wounds studied. Again, the difference may have been attributable to the different season at which the two factories were studied: A in the autumn and early winter, B in the late winter. We have no direct evidence about the influence of season on infection of these wounds but the surgery records at $A$ for the past 3 years show no consistent seasonal change in the ratio of new attendances of patients with cuts that are septic when first seen to those with cuts that are clean when first seen. It seems unlikely, therefore, that a difference of the observed magnitude is attributable to seasonal variation.

In summary, taking into account our own and other workers' experience in studying cross-infection in hospital, we believe that the difference in aseptic methods made a substantial contribution to the observed difference in infection rates.

Manifest sepsis was not a common complication in either series of wounds; the majority of the infections -were unaccompanied by clinical signs. These ' silent' infections are, however, important in three ways: (1) there is some evidence (Table 8 and unpublished work, see Miles, 1944) that the infection leads to delay in healing; (2) the wounds so infected constitute a large and unrecognized source from which pathogens may be transferred to

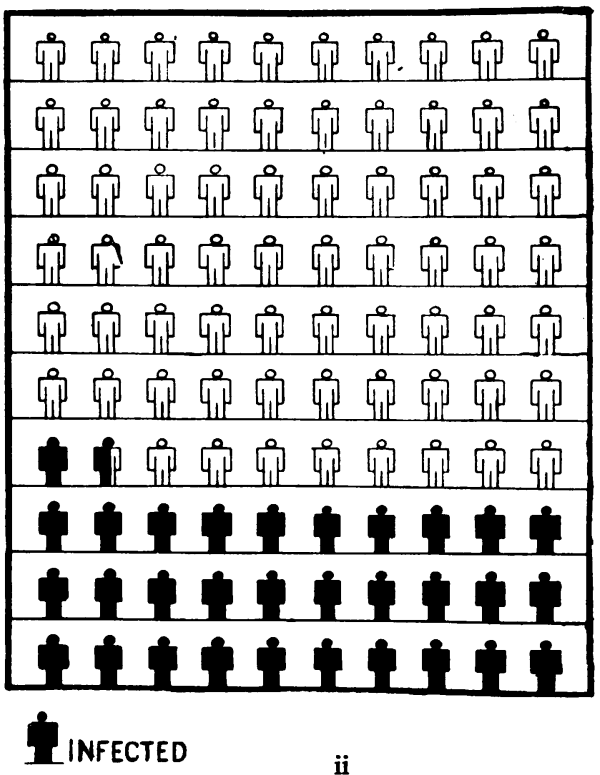

$\underline{\underline{m}}$

c

$\frac{1}{2}$

ఫृ

家

(⿻)

$\overrightarrow{0}$

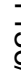

要

胥

in

c)

के

윽

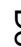

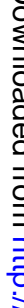

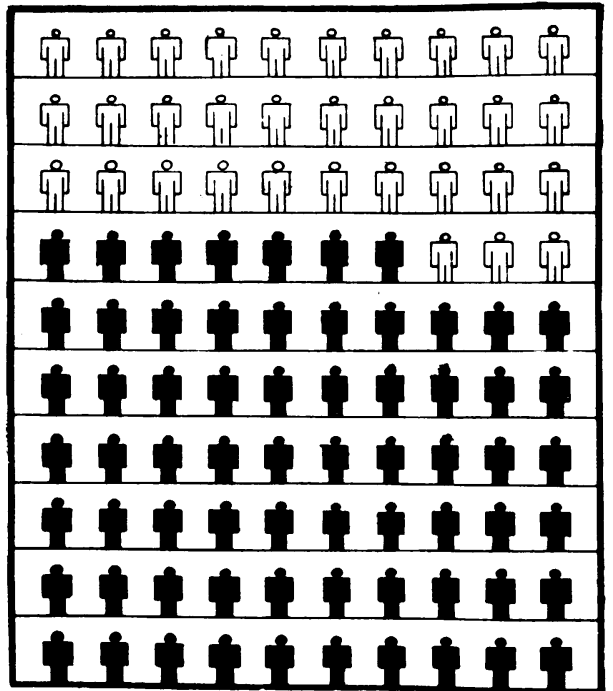

进UNINFECTED

Summary Diagram.-A comparison of the percentage incidence of infection by pyogenic cocci in wounds seen one or more times after the initial attendance, in two factories employing different dressing techniques: (i) handling the wounds, and (ii) using a modified 'no-touch' technique (see page 148). 
other, perhaps more susceptible, wounds; and (3) silent infections may on occasion become manifest later and the resulting sepsis lead to considerable disability. It is impossible to foretell the consequences of silent infection, either for the patient or for others, and though it is probable that in most patients the effect is small, the more serious consequences can only be guarded against by methods designed to reduce all added infection, whether silent or manifest.

In our opinion, the results clearly indicate the necessity for aseptic methods in handling even the small wounds that constitute the majority of those treated in the surgeries of engineering factories. A set of rules for such an aseptic routine has been outlined by one of us (Williams, 1944) and the performance of the routine is often facilitated by some reorganization of the lay-out of the surgery (Gissane, Miles, and Williams, 1944). We may note in this connection that the revision of aseptic measures that we have advocated has been proved to be practicable by a number of nurses in charge of large factory surgeries in Birmingham.

\section{Summary}

Of 531 small wounds and septic lesions examined in the surgeries of 19 different factories, 48 per cent. were infected with pyogenic cocci. In general, the older the wounds the higher was the infection rate.

A detailed comparison of $\mathbf{4 7 2}$ wounds treated in two factories engaged in similar work, but where different dressing routines were followed, showed that the incidence of infection was less in the surgery where the wounds were treated with a relatively rigorous no-touch dressing technique. In the surgery with the higher infection rate, where the wounds were handled more freely, the obvious deficiencies in the dressing routine were of the kind that would facilitate the spread of pyogenic microbes from one patient to another and it is highly probable that cross-infection of this kind was responsible for a substantial part of the difference in infection rates.

The extra burden of infection associated with the less rigorous technique is not primarily an indication for the adoption of a full aseptic routine since, in the small wounds studied, infection did not notably increase the average disability to the patient. Nevertheless the high incidence of infection indicates the existence of a risk which, in the long run, will manifest itself in occasional severe infection, particularly of large wounds; a risk which, in our opinion, can be substantially minimized by the adoption of a simple but rigorous routine of dressing.

\section{Acknowledgments}

Our thanks are due to the medical officers and nursing staffs of all the factories that we have visited, but particularly to those of the two factories where the detailed comparison was made, for the continuous co-operation that made the investigation possible.

We are also indebted to Dr. A. Bradford Hill for assistance in the analysis of the results, and to $\mathrm{Dr}$. Donald Stewart and Dr. J. M. Davidson (lately H.M. Medical Inspector of Factories in Birmingham) for introducing us to many of the factories.

\section{REFERENCES}

Annual Report of Chief Inspector of Factories (1942). H.M.S.O.,

Gissane, W., Miles, A. A., and Williams, R. E. O. (1944). Brit. J. industr. Med., 1, 90

Medical Research Council, War Memorandum No. 6 (1942). The prevention of 'hospital infection' of wounds. H.M.S.O., Lond.
H. infection in hospitals. H.M.S.O., Lond.

Miles, A. A. (1944). Lancet, i, 809. Schwabacher, H., Cunliffe, A. C. Ross, J. P. Spooner, E. T.C. Pilcher, R. S., and Wright, J. (1940). Brit. med. J., ii, 855, 895 .

Mock, H. E. (1915). Surg. Gynec. Obstet., 21, 481.

Spooner, E. T. C. (1941). J. Hyg., Camb., 41, 320.

, Clayton-Cooper, B., Howat, T. W., and Miles, A. A. (1945). 32, 425.

and Miles, A. A. (1945). J. Path. Bact., 57, 27. 